\title{
The Chinese Women Participation Right in Antagonistic Sports Event between Urban and Rural Areas
}

\author{
Xiaoxue Liu ${ }^{1}$, Yanfen Zhang ${ }^{2}$, and Xuezhi Ma ${ }^{3}$ \\ ${ }^{1}$ Department of Physical Education, China University of Geosciences, Xueyuan Road, Haidian \\ District, Beijing, P. R. China \\ ${ }^{2}$ Department of Life Sciences; Xinxiang University, Xinxiang Henan province, Eastern Section of \\ Hua Lan Road, Hongqi District, Xinxiang City, Henan, China \\ ${ }^{3}$ Beijing Sport University Wushu School, Information Road, Haidian District, Beijing, China \\ xxliu8888@aliyun.com,1421185078@qq.com,malaoshide21@sohu.com
}

Keywords: Social Status Gap, Chinese Women, Appeal for Participation Righ, Antagonistic sports event, Sports Right

\begin{abstract}
From the perspective of Chinese women's improving social status, this article explores the relationship between the changes in social status of Chinese women and their participation in antagonistic sports event and aims to fight against the behavior of keeping woman out of antagonistic sports event(For example, China's Wushu and striking skills. In fact, an active participation in antagonistic sports event not only helps Chinese women understand the relationship between their sports right and social status, but potentially encourages Chinese women to obtain the sports right and social status they deserve.
\end{abstract}

\section{Chinese Women's Emancipation In Politics, Education and Economy}

Under the rule of feudal patriarchal system for thousands of years, the ideology that men were considered superior to Chinese women has always dominated China. However, with the implementation of the reform and opening up policy, China has gained tremendous development, and the social status of Chinese women is under the protection of the Constitution and other laws and regulations. Now Chinese women enjoy equal rights as men do, especially which their political rights are greatly guaranteed by laws. Besides, Chinese women's social status has been largely improved, so does their political awareness as well as their participation in managing state and social affairs. In terms of politics, the Chinese government organs at all levels pay high attention to Chinese women's participation in the administration and discussion of state affairs. Meanwhile, Chinese women accounts for a growing proportion among cadres in autonomous regions, grass-roots community's neighborhood committees and village committees. In terms of economy, removing female employment problems is the key to Chinese women's economic independence which largely contributes to the improvement of Chinese women's social status. In addition, female employment, Chinese women's proprietary right and the establishment and improvement of social systems are the prerequisites to the equality between men and Chinese women and the improvement of Chinese women's social status as well. In terms of education, since 1960s, China, inspired by ethos like educational democratization, has begun to perfect its educational law system, which has 
greatly promoted Chinese women's access to education. With the continuous increase in productivity level in China and the demand of social development, the right to receive education becomes a basic right for everyone, just as what stipulated in The Educational Law of the People's Republic of China, "Chinese women and men have equal rights to receive education". Since then, the educational work relevant to Chinese women gains extensive support, which facilitates the perfection of female educational system, enhances Chinese women's personal qualities and lays a solid foundation for the improvement in Chinese women's social status. In terms of marriage and family, Chinese women's social status and economic capacity determine their status in the marriage or family. As the economic filed that Chinese women involve in further expands, Chinese women gradually break away from their dependence on men especially economically and they also become the family supporter just like men do. Thus, Chinese women's economic status and status of household operation in the family is increasingly improving, and that both men and Chinese women talk over family affairs and manage family budget has become a common social phenomenon.

\section{A Gap In Chinese Women's Social Status Among Different Regions in China}

In the modern society, Chinese women, whether in politics, economy, education or marriage and family, their status has gained unprecedented improvement. Enlightened by feminist movements, Chinese women have deeply realized that men and Chinese women are born equal. Under these circumstances, Chinese women begin to go out of the family and step into the outside world where they try hard to achieve those desirable values of life. The tenacious quality peculiar to Chinese women contributes to their success in political, financial and educational circles. Nevertheless, some problems still arise during the process of improving Chinese women's status. For example, the gap in social status between Chinese women in urban and rural areas has attracted the public attention. It's common that traditional ideas still has an influence on rural females. When reviewing the history of human development, Chinese women in old days before the founding of New China had always suffered from social discrimination and household constraints. There are some old sayings improperly describing Chinese women's status and their roles in the family, such as "ignorance is a woman's virtue", "The Three Obediences and Four Virtues" and "woman is responsible for assisting her husband and teaching her children", which to a great extent becomes the bottleneck for Chinese women's participation in politics. Compared with rural females, urban females enjoy a much more colorful life. Although in professional and vocational organizations, Chinese women account for a smaller part than men do, statistics shows that the proportion that Chinese women participate in non-professional organizations is larger than that of men. This implies that the modern Chinese women's consciousness to participate in politics in urban areas is much higher than Chinese women in rural areas. According to the sample survey co-conducted by the National Bureau of Statistics of China and the All-China Women's Federation, in recent 20 years, the number of female entrepreneurs is increasingly rising. Among the surveyed female senior managers, $95 \%$ of them have become managers after the implementation of the reform and opening up policy, among which 57\% got the post of senior manager after 1990 .

Chinese women's educational status, an important symbol of Chinese women's social status, is not only closely associated with their personal development and the education of the next generation, but has an impact on the political, economical, vocational and household status that they deserve. More importantly, men and Chinese women have equal rights to receive education, directly showing the overall situation of gender equality in a country or a region. Therefore, the improvement of Chinese women's educational status is conducive to improving their social status on the whole, which can meet the requirements of social development, and simultaneously, Chinese women can enjoy the basic rights for personal development. However, the political activities and 
jobs Chinese women involve in explain the fact that urban females receive much higher education than rural females due to the disparity in economic development between urban and rural areas. Whereas, the income gap between husbands and wives directly affects the education that Chinese women receive, and it is believed that the low income rural females earn and the large income gap between the couples are the major causes for the low educational status of rural females.

\section{Chinese Women Should Enjoy Higher Sports Right}

Pierre de Coubertin, the initiator of modern Olympics, was strongly against Chinese women's participation in sports all his life. As one of the most competitive sports events and one of the most eye-catching competitions in Olympic Games, antagonistic sports event(For example, China's Wushu and striking skills) indeed reshapes a man-oriented system where antagonistic sports event continuously reminds people that men are physically stronger than Chinese women by nature. Such an idea is doomed to result in a worse situation that men's sense of superiority in sports will be transferred into other fields (Kane M. J., Snyder E., 1989.). Based on the theory of French philosopher Michel Foucault, we can explore to a deeper layer that body is endowed with meaning by discourses which constitute the body and represent body discipline (Li Xiaozhi, 2012.). As a result, the so-called masculinity and femininity and the subordinate status Chinese women belong to in antagonistic sports event is nothing but something structured by the society and culture and the patriarchal system. Men dominate the sports events, so the establishment of discourse right is mainly man-oriented. For instance, Ben Weider and Joe Weider, the initiators of Professional Men Bodybuilding Competition in 1949, identified the rules of bodybuilding and advocated the physique and aesthetic perception of body builders in their magazine, which is a typical example that man controls the discourse right. Such a competition and magazine started by men are surely partial to the sense of muscles and potency of physique. In this case, Chinese women are forced to comply with men's aesthetic preference toward bodybuilders(Messner M. A., 1988.). Hence, the sports field is filled with traditional muscle ideology mainly in the form of vigor, competition, occupation and victory. Particularly, the highly competitive antagonistic sports event(For example, China's Wushu and striking skills) has never been a self-choice for Chinese women but always a priority for men. Traditional gender discrimination excludes Chinese women from participating in the violent antagonistic sports event(For example, China's Wushu and striking skills). However, more and more female antagonistic sports event(For example, China's Wushu and striking skills) players tend to be masculine in order to meet the requirements in muscles and strength(Blinde E., Taub D., 1992.). Feminists indicate that this phenomenon shows the fact that people deny the "status" right of female athletes and neglect their personal gender orientation. Although men are in control of the discourse right in sports, and female sports are besieged by male power, feminists are still making great efforts to display the physical features of Chinese women and call on people to consider our body as a cognitive symbol for profound understanding of our body and ourselves(Richman E. L., Shaffer D. R., 2000.). Only in this way can Chinese women enjoy a feminism-based discourse right and obtain more rights in the sports filed or even in the whole society so as to fight against the men-dominant social system.

Over the past few decades, the proportion of Chinese Chinese women taking part in antagonistic sports event(For example, China's Wushu and striking skills) has been rising dramatically along with which people's attitude toward female antagonistic sports event(For example, China's Wushu and striking skills) has been changing as well. Nevertheless, some Chinese women dislike the female body full of strength and muscles and refuse to join the vigorous antagonistic sports event(For example, China's Wushu and striking skills). Researches show that Chinese women participating the more "feminine" sports are much more sensitive to gender difference, and they pay 
more attention to their body image just like the cheering squad whose cheer is merely an appendant of the male match all the time. Just as professor and body builder Highwood stated in her book, "for whatever purpose, I always believe the muscles a woman obtains in sports can strike a powerful counter-blow against the man-oriented traditions." Her opinion "the muscles obtained in sports is not merely the outside body, but the control of the initiative and Chinese women's body self-cognition” reflects the recognition of personal identity.

\section{Chimese Women's Access to Antagonistic Sports Event}

Antagonistic sports event, as one of the most masculine sports (featuring muscles, explosive force, and aggressiveness) in the world, is irrelevant to Chinese women by rights, however, the number of Chinese women participating in antagonistic sports event(For example, China's Wushu and striking skills) is keeping rising in Chinese. Since antagonistic sports event requires strength, Chinese women involved in this sport can obtain muscles and sense of lines through training, breaking the stereotype that Chinese women are delicate and need protection from men. From the perspective of physical image, this urges man to offer Chinese women the deserved equality and respect. Moreover, the toughness, competitiveness and aggressiveness that sports possess may help cultivate Chinese women's tenacity and initiative. Compared with Chinese women never participating in sports, those who participate are much more tenacious and competitive in all fields. Since they have better understanding of their body and are tenacious and active in spirit, even if men mark them as "lesbians" for their involvement in highly competitive sports. Female sports participators and female athletes will not become the victims to men again. On the country, they will adopt a more open gender value to deal with this problem. For example, Chinese women will form organizations to protect their rights, and fight against the behavior of taking muscles and body curve as the only standard to evaluate personal identity. Feminists hold the opinion that female sports participators have a more open attitude toward gender, making for a higher happiness index. They have different understanding of their bodies during sports, so they are not willing to be at the mercy of the society. As a matter of fact, they have higher expectations in achieving self-value and have better self-consciousness. In this sense, after taking part in antagonistic sports event(For example, China's Wushu and striking skills), Chinese women feel their bodies are much closely related to themselves, and they have a higher sense of competition than before. Combined with their healthy image, self confidence and the open attitude, Chinese women are no longer controlled by men, whereas they win much more respect and gain a higher social status. Whether a woman is good-looking or not lies in the identification of other females rather than the femininity recognized by the society. For Chinese women, they participate in sports no longer for the compliment of men but more for self-appreciation. One the one hand, antagonistic sports event emancipates Chinese women's body; on the other hand, it encourages Chinese women to better understand what a competitive body, a healthy image or a free mindset is like, and improves their self-consciousness and self-esteem. Through practice, Chinese women can obtain personal identity, which prevents them from loosing self-identity, and arouses men's attention to Chinese women and help them obtain the higher social rights.

\section{Conclusion}

Since Chinese women's physical concept is constructed by the patriarchal society, Chinese women are unable to have a comprehensive understanding of themselves. As a result, they fall into the appendant of men, and there appears discrimination against Chinese women and women's loss in power. However, under proper understanding and cognition of their physical status, men are in power and dominate the world. In view of this, our physical body reflects the relationship of social 
power in which body is the key to status. As a way for body practice, antagonistic sports event(For example, China's Wushu and striking skills) enables Chinese women to know their body, become physically stronger and break the figure boundary between man and woman. Though antagonistic sports event(For example, China's Wushu and striking skills) is still a field controlled by male power, there occurs a popular phenomenon that more and more Chinese women are participating in antagonistic sports event(For example, China's Wushu and striking skills) through which Chinese women have a deeper understanding of their body. They combine self-competition with their physical body in antagonistic sports event(For example, China's Wushu and striking skills), and remove the obsolete social customs and ideas to achieve higher self-consciousness and self-value, obtaining Chinese women's discourse right in antagonistic sports event(For example, China's Wushu and striking skills) field and seek equal social status and rights as men do. More importantly, when Chinese women's rights in sports are fully achieved, Chinese women may transfer their sense of superiority into other fields so that they can gain more social rights to fight against the man-dominant social structure.

\section{Acknowledgements}

This paper is supported by "Project of the humanities and social sciences research program of the Ministry of education of China" (15YJA890016), Basic scientific research projects in Chinese Universities (2-9-2015-417) and China University of Geosciences (Beijing) key project of teaching reform (JGZHD201711).

\section{References}

[1] Blinde E., Taub D., 1992. Women Athletes as Falsely Accused Deviants: Managing the Lesbian Stigma, Sociological Quarterly. 4 (33), pp. 521-533.

[2] Kane M. J., Snyder E., 1989. Sport Typing: The Social “Containment” of Women in Sport, Areana Review. 2 (13), pp. 77-96.

[3] Messner M. A., 1988. Sports and Male Domination: the Female Athlete as Contested Ideological Terrain, Sociology of Sport Journal. 3, pp. 197-211.

[4] Richman E. L., Shaffer D. R., 2000. If You Let Me Play Sports: How Might Sport Participation Influence the Self-esteem of Adolescent Females, Psychology of Women Quarterly. 2 (24), pp. 189-199.

[5] Xiaozhi Li, 2012. The Enlightenment of Foucault's Body Theory on Sociology of Sports, Physical Education and Sports. 2 (33), pp. 24-27. 